\title{
Migration, Remittances, Poverty, and Human Capital: Conceptual and empirical challenges
}

\author{
David McKenzie ${ }^{*}$ and Marcin J. Sasin ${ }^{* *}$
}

\begin{abstract}
$^{* * *}$
This paper reviews common challenges faced by researchers interested in measuring the impact of migration and remittances on income poverty, inequality and human capital (or, in general, "welfare") as well as difficulties confronting development practitioners in converting this research into policy advice.

On the analytical side, the paper discusses the proper formulation of a research question, the choice of the analytical tools as well as the interpretation of the results, in the presence of pervasive endogeneity in all decisions surrounding migration. Particular attention is given to the use of instrumental variables in migration research.

On the policy side, the paper argues that the private nature of migration and remittances implies a need to carefully spell out the rationale for interventions. It also notices the lack of good migration data and proper evaluations of migration-related government policies.

The paper focuses mainly on microeconomic evidence about international migration, but much of the discussion extends to other settings as well.
\end{abstract}

World Bank Policy Research Working Paper 4272, July 2007

The Policy Research Working Paper Series disseminates the findings of work in progress to encourage the exchange of ideas about development issues. An objective of the series is to get the findings out quickly, even if the presentations are less than fully polished. The papers carry the names of the authors and should be cited accordingly. The findings, interpretations, and conclusions expressed in this paper are entirely those of the authors. They do not necessarily represent the view of the World Bank, its Executive Directors, or the countries they represent. Policy Research Working Papers are available online at http://econ.worldbank.org.

\footnotetext{
${ }^{*}$ David McKenzie is currently a Senior Economist in DECRG department of the World Bank.

${ }^{* *}$ Marcin Sasin is currently an Economist in PREM Poverty group of the World Bank.

*** This paper has benefited from comments provided by participants of the World Bank Migration and Development Thematic Group Seminar on September 21, 2006. Pierella Paci, Catalina Gutierrez, Katy Hull and Edmundo Murrugarra contributed further useful comments. The work has been guided and supported by Louise Cord, Manger, and Luca Barbone, Director of PREM Poverty group. For more information see: www.worldbank.org/migration
} 


\section{INTRODUCTION: RAISING THE PROFILE OF MIGRATION}

The purpose of this paper is to provide guidance to interested researchers and development practitioners on how to measure the impact of migration and remittances on income poverty, inequality and human capital (or, in general, "welfare").

Migration is a huge phenomenon. The share of migrants in industrial countries' populations doubled over past three decades and remittances flows to developing countries are larger than foreign investment or overseas aid. In many developing countries the percentage of the population working abroad and the percentage of GDP represented by remittances run into double digits.

Policymakers in affected countries do not always fully appreciate the challenges and opportunities which migration brings to the development process and, when they do, are often in the dark about which policies can enhance the impact of migration on development. Sound research and successful advice based on it can raise the profile of migration in governments' agendas and inform policy choices.

This paper deals mostly with international migration. Many of the impacts on welfare and issues of measurement and estimation methods discussed here apply equally to internal migration. However, the policies needed for countries to maximize the welfare benefits of international migration can be quite different from the policy responses needed for internal migration.

This note has four general messages:

- The research question should be given adequate consideration. In principle, a broad question, e.g. "what is the impact of migration on poverty/human capital?" (as opposed to a narrower question about, say, the impact of remittances only) is more appropriate, given the complexity of relationships involved.

- The pervasive endogeneity in decisions surrounding migration requires more advanced techniques, e.g. instrumental variables, which deal with this issue explicitly.

- Since remittances are private money and migration is a private decision, policy recommendations should spell out the rationale for interventions, pointing to market failures that cause the private returns to migration and remittances to diverge from the social returns.

- A realistic contribution to current knowledge can be made through collecting better migration data and evaluating the interaction between migration and government policies.

In the next section, we discuss channels by which migration impacts welfare and consider typical questions asked in operational research on linkages between migration and poverty or human capital. In the third section we consider appropriate methodological approaches, given the analytical challenges of establishing and measuring causal relations that include migration. In the fourth section we consider how to convert research into policy recommendations. 


\section{MIGRATION AND WELFARE: LINES OF INQUIRY}

\subsection{Gauging the importance of migration}

Is migration, in a given country, important in the first place? The relevant indicator of the importance of migration would be the share of households having a migrant or a share of remittances in total income - as obtained from a household survey. In the case of the latter, when the survey is not available upfront one may consult the balance of payment statistics (BOP). As a rule of thumb, remittances obtained from the BOP equal 1.5 times those obtained from the household survey, with a correlation of .90 (Acosta, Calderon Fajnzylber and Lopez, 2006a). Nevertheless, a given country may be an outlier, so one may check also with other sources, for example a comprehensive estimate of bilateral stocks of migrants for 226 countries and territories compiled by Global Trade Analysis Project (GTAP, 2005), the OECD's Database on Immigrants and Expatriates (OECD, 2005) containing detailed information on the foreign-born population for almost all member countries of the OECD, the Docquier and Marfouk (2004) as well as Beine, Docquier and Rapoport (2006) databases on migration by education (and age of entry) from developing countries to OECD countries or Bhargava and Docquier (2006) Database on the International Migration of Physicians. These figures should provide a first glance at the extent of migration.

\subsection{Identifying channels of impact and relevant questions}

The transmission channels through which migration and remittances impact various living standards and human capital outcomes are numerous. The most obvious is the income channel, namely that remittances directly contribute to total income. Remittances should lead to increased consumption and investment, implying a positive effect on poverty reduction and human capital. The less obvious channels include interactions with government policies, consequences of parental absence, consequences of removing entrepreneurial individuals from the community. As a result of these various effects, the direction of the impact of migration on poverty, inequality and human capital is not predetermined and becomes an empirical question.

Accordingly, the following types of questions are common in operational research on migration-welfare links ${ }^{1}$ :

- Who is receiving remittances (the poor or the rich)?

- Do remittances/migration alleviate poverty? And if so, how?

- Do remittances help smooth consumption and alleviate a credit constraint, thus preventing risky coping strategies of disinvestment?

- Do they provide income diversification and insurance, thus encouraging higherrisk-higher-return activities?

- Are remittances spent on consumption or investment?

\footnotetext{
${ }^{1}$ These research questions, extracted in an ad hoc review of selected literature (see references section) are presented in no particular order.
} 
- Do migrant families spend more on health and education?

- Are migrants' children healthier and more likely to remain at school (instead of, say, working)?

- What is the gender impact, do daughters in migrant households go to school?

- How do existing government programs impact migration, and how does migration affects those programs?

This note argues that while most of these questions have intrinsic worth, some of them are of lesser value when posed in isolation, particularly if one is interested in the broad poverty-reducing impact of migration. The principal question in most operational research should rather be a general one - what is the impact of migration on poverty and/or human capital? - which accurately reflects the complexity of the relationships involved.

\section{ANALYTICAL CHALLENGES IDENTIFYING IMPACT}

Analytical work on the impact of migration is made more complex by three sets of challenges. The first group of issues is related to data and definitions. The second group relates to the intrinsic endogeneity and selectivity involved in decisions surrounding migration. Finally, the third group of problems arises due to the multiple indirect socioeconomic effects of migration. These issues, discussed below in more detail, have implications for the formulation of appropriate research questions and the design of methodologies.

\subsection{Data and definitions}

As regards data, the minimum requirement is to have a variable in the survey indicating whether a household has a migrant. Information on the amount of remittances is helpful but not essential. These two variables constitute a migration "module" in a typical household survey. However, several World Bank's Living Standard Measurement Surveys (LSMS) pay more attention to migration issues.

Obtaining other, non-survey data, such as administrative statistics on socioeconomic characteristics of villages/regions can, as discussed later, significantly contribute to the explanatory power of research, by helping to control for "other factors" and to construct alternative identification strategies.

Panel data can enormously improve the situation. By taking differences one can address many biases that arise due to omitted variables (including unobservable individual characteristics), selection or endogeneity.

If one has control over the design of the survey, then (without going into too much detail) useful ideas are: i) oversampling migrants; ii) introducing retrospective questions about pre-migration characteristics (income, work history) to enable construction of better counterfactuals; iii) collecting information on migration locations within destination countries; iv) surveying both areas of origin and areas of destination. 
Finally, having seen the data, one needs to define a migrant. In many cases it will be straightforward, but some data will allow for multiple definitions (temporary, circular, seasonal, internal). The way forward is usually to choose the most intuitive and acceptable definition and later check sensitivity of results to a change in the definition.

\subsection{Endogeneity}

Decisions on migration, remittances, labor supply, expenditure allocation, school attendance, child labor and so on are usually made simultaneously. Hence, characteristics which "explain" migration or remittances may also shape household expenditure patterns, education and healthcare choices, etc. Moreover, many of the characteristics which influence these decisions are unobservable (e.g. "ability" or risk aversion). These issues make it difficult to establish causality and bias the typical reduced form regression framework.

Major concerns outlined here are i) reverse causality; ii) selection bias; and iii) omitted variables.

i) Reverse causality arises when an outcome influences migration or remittances, not vice versa. If, for example, remittances are sent to cushion bad economic (or health) shocks one might find a positive relation between remittances and poverty (or health outcomes) and be tempted to draw the wrong conclusions.

ii) Selection bias arises because migrants can differ fundamentally from non-migrants they "self-select". Therefore, one can't determine what would happen to non-migrant households if they migrate, just by looking at the experience of migrant households (or vice versa). For example, healthier, more educated and wealthier households might be more likely to migrate ("positive selection") or less likely to migrate ("negative selection").

iii) When migrants self-select for migration on the basis of unobservable characteristics (or if important variables are not included in the model) one finds omitted variables bias. For instance, sound economic policies could simultaneously lead to a reduction in poverty and attract remittances intended for investment in the local economy, so that poverty and remittances would be negatively correlated without a causal relation (Taylor and Mora, 2006). Similarly, a crop failure could reduce income and cause migration at the same time. Or "ability" could positively influence both income potential and propensity to migrate.

\subsection{Other things going on: the broader socioeconomic effects of migration}

Other socioeconomic effects of migration that differ from the pure effect of remittances include (but are not limited to) the following. There is lost income of a migrant, which may or may not be offset by lower consumption needs (absence of an "eater"). Household labor supply might change. So can the set of opportunities. Moreover, migrant households may face different prices of community participation, e.g. by raising 
expectations that a migrant would contribute more or help others. Migration can disrupt family life by putting emotional stress on children, leaving them with less supervision or forcing them to take up more household work - all with negative consequences for their learning. Successful migration of others can change expectations of returns to education and (positively or negatively) influence schooling decisions (Mansuri, 2006a). Migrants can transfer knowledge about better technologies (leading to more income and less poverty) or bring more awareness of health/education issues (leading to better human development outcomes). All these channels should be acknowledged in the analysis.

\subsection{Getting the question right}

Often the starting point for research is a question such as "what is the impact of remittances on poverty/health/education?" In light of the above discussion, the initial research question might need reconsideration. We argue strongly that one actually cannot (in most cases) separate remittances from migration, because these phenomena are intertwined and endogenous. In fact, it is not immediately clear why one would want to separate them and what the pure "impact of remittances" would mean or imply.

The question "what are remittances spent on?" may also be difficult to answer, since money is fungible. In other words, why would remittances be spent in any different manner than normal income? In theory, increased income helps to buy more of all normal goods, including health and education. If a poor household consumes $80 \%$ of its total income, so would it consume about $80 \%$ of income from remittances.

There are, however, two possible - if poorly measured - reasons as to why remittances may differ from labor income. First, the permanent income hypothesis suggests that if income is temporary, the chance that it will be saved (or invested) is higher. ${ }^{2}$ Second, remittances may be earmarked for a specific purpose (perhaps investment rather than consumption) and these conditions may be binding. Additionally, policymakers may want to know whether remittances have a separate effect from migration, for example when choosing between policies encouraging more migration (a controversial area) and encouraging more remittances (much less controversial). In these cases, the research question about the "impact of remittances" gains validity. However, empirical determination of this question rests on identifying why two otherwise identical migrants remit different amounts, which in most cases is not feasible.

Therefore, where there are no compelling reasons and credible means to analyze the impact of remittances in isolation, a "holistic" approach - enabled by the question "what is the welfare impact of migration?" - is the most appropriate, honest and simple starting point.

\footnotetext{
${ }^{2}$ Indeed, research shows that both migrants and their families expect remittances to decay over time (e.g. McKenzie, 2006).
} 


\subsection{Getting the answer right}

As indicated above, arriving at the answer to a "migration question" may require sophisticated methods. The choice of method will depend on the availability and quality of data as well as the research question. For example, the question "are migrants' children healthier?" requires a different approach to the question "does migration improve children's health?" Attention should be paid to whether the interpretation of the results of a given method is consistent with the research question.

Below, we have liberally grouped possible approaches into five broad categories.

\subsubsection{The almost-ultimate answer - a randomized experiment}

A genuine and well designed randomized experiment would randomly deny a determined migrant-to-be the right to migrate, thus creating a "control group" of individuals with the same profile as migrants but without the option of moving. As regards interpretation, comparing the outcomes of interest of the two groups yields precisely the (causal) effect of migration.

Interestingly, such experiments exist, usually in the form of visa lotteries (see McKenzie, Gibson and Stillman, 2006, analyzing a New Zealand visa lottery for Tongans). In some developing countries some government programs also involve an experimental design. One can exploit this design to measure the effect of government interventions on migration decisions (see e.g. Angelucci, 2005 or Stecklov, Winters, Stampini and Davis, 2003, on the impact of Mexican Progresa on migration). However, experiments are rare, so one is usually left with non-experimental econometrics only.

\subsubsection{Ignore causality, go for crosstabs}

Crosstabulations of migration or remittances versus outcomes (e.g. poverty or education) can be informative by providing a description of the situation. In tabulating remittances by income deciles it makes sense to first deduct remittances from total income, before constructing poor/rich rankings. Of course, this approach treats remittances as exogenous. Another "naïve" approach is to simply ask migrants (or their families) the purpose for which remittances are sent (spent) and tabulate the results. This, however, completely ignores the issue of fungibility of money. These tabulation methods, by displaying averages only, do not identify causal relations and provide rather weak grounds for policy recommendations.

\subsubsection{Believe the OLS (ordinary least squares)}

The common approach is to regress the outcome of interest on a migration variable and a set of control variables, that is: outcome $=\alpha+\beta^{*}$ migration $+\gamma^{*} X+\varepsilon$. This assumes that some households just happen to migrate or receive remittances (like manna from heaven) thus ignoring endogeneity, so the coefficient $\beta$ is (most likely) biased. However, if one has grounds to believe this bias is small, OLS method might be satisfactory. 
One can apply selection methods such as the Heckman selection model to the OLS framework to try and correct for possible selection bias. However, such methods either require the identification of an instrumental variable (see below), or more typically, rely on functional form assumptions that can be a weak basis for policy recommendations.

A comment on the choice of the specification and variables is in order. First, the model should entail the proper causality, otherwise coefficient $\beta$ would be meaningless. Second, for the reasons stated above, the migration variable, if possible, should be indicating migration status rather than related phenomena, such as the amount of remittances. Third, the model should include all relevant variables - all of them exogenous. Specifically, it should not include variables that are impacted by migration. Recall that the interpretation of OLS results would be "the impact of migration on the outcome (say, children's education), holding all control variables constant". So, if income is included among control variables, the interpretation would imply "impact of migration on children's education holding income constant", which is not necessarily what one would like to measure. However, including pre-migration income could improve the model, controlling for household wealth status.

\subsubsection{Reconstruct the counterfactual}

The fundamental problem in identifying the impact of migration is a lack of a counterfactual, so one way forward is to try to (re-)construct it.

One approach is to "manually" reconstruct what a household's situation would have been had a household member not migrated. For example, when we are interested in income, we would deduct remittances, add (impute) a hypothetical income had a migrant stayed, and correct (impute) the labor participation decisions (and, hence, incomes) of other members. The imputation part is problematic. Can we use the non-migrant earning function to predict home earning of a migrant, even if correcting for selection on observable characteristics? Should we use average or marginal earnings? ${ }^{3}$

When interested in the impact on inequality, in addition to the procedure outlined above, one would ideally add to the imputed income a non-insignificant random error component with the same variance as in the estimated income equation and average it over, say, a thousand of repetitions to get the mean impact (and standard errors as a byproduct, see e.g Acosta, Calderon Fajnzylber and Lopez, 2006b).

A second approach is to compare a migrant household to an "identical" household that has not migrated. Obviously, the "identical" household does not exist, but by using a propensity score matching technique we can equally well compare to a non-migrant household with the same propensity to migrate. This means running a migration decision regression. The typical migration determinants are age, sex, education, existing migrant networks, household composition, and wealth. The last one is most likely to be itself

\footnotetext{
${ }^{3}$ In the agricultural setting a marginal productivity of a migrant at home can be close to zero. In this case we should control for household composition when estimating the earning function. Similarly, in the high unemployment settings a migrant at home might not be able to get any job at all.
} 
affected by migration, and so one ideally needs to control for pre-migration household wealth. Alternatively, one can try to approximate it by certain household assets that are less likely to be affected by current remittance flows and more likely to reflect long term wealth, such as housing amenities (see e.g. Acosta, 2006). When done well, propensity score matching can lead to a significant improvement over the OLS estimates.

\subsubsection{Going around the problem: working in differences and instrumental variables}

A major advantage of panel data or data with retrospective variables is that it allows control for issues of time-invariant unobservable characteristics. When only a migrant sample is available a single difference estimator can compare post-migration income to pre-migration income and take the average difference as a mean impact of migration. This estimator could be corrected by a mean change in the home country income. When a panel includes both migrants and non-migrants, a double difference (difference-indifferences) estimator directly estimates gains from migration (if the model is correct), for example in the following regression: $\Delta$ outcome $_{i}=\alpha_{i}+\beta^{*}$ migration $_{i}+\gamma^{*} X_{i}+\varepsilon_{i}$.

Use of instrumental variables is prevalent in the research on the impact of migration. A powerful instrument can eliminate problems of endogeneity, omitted variables and measurement error. Yet the technique can be deceptive. Below we will discuss its application to migration in greater detail.

How does the instrument work? The direct source of bias in the OLS estimator is a violation of the independence of explanatory variable (say, migration) from the error term in the equation. Suppose that ability influences both migration and an outcome of interest (say, income). However, since ability is unobserved it ends up in the error term, which now becomes correlated with migration. By finding a variable (an "instrument") that is correlated with migration but uncorrelated with ability (or, equivalently, it is uncorrelated with income for reasons beyond its effect on migration) one can "split" the variation in migration and "use" only the part uncorrelated with the error term.

How to find a good instrument? Technically speaking an instrument must be relevant (correlated with the explanatory variable) and exogenous (not correlated with the dependent variable other than through the explanatory variable). Instrument relevance is testable (by regressing the outcome on the instrument), while instrument exogeneity, in principle, needs to be "argued". The instrument should not be "weak" (i.e. weakly correlated with the explanatory variable), so an F-statistic below 10 may be a cause for concern (Staiger and Stock, 1997). One instrument is often preferable to a set of them (Angrist and Krueger, 2001).

In reality, as Angrist and Krueger (2001) argue, good instruments often come from detailed knowledge of the economic mechanism and institutions determining variables of interest. A very popular method is to look for "natural experiments", where a force majeure (natural shocks or a blunt government intervention) causes an exogenous change in an otherwise endogenous explanatory variable. In the context of migration we need to think of reasons why one household may have a migrant and another "identical" 
household would not. For example, theory (and common sense) dictates that migration depends on the net benefits from migration. So a variation in migration costs caused by exogenous factors (such as a distance to the border or government policies unrelated to migration potential) can possibly provide good instruments. That is why complementing surveys with other data may improve the analysis.

What instruments have been used? Variables used to instrument for migration vary according to both data availability and the outcome of interest. A variable that might plausibly be a valid instrument when looking at outcomes for migrants abroad may not be suitable as an instrument for looking at outcomes among migrant families remaining in the home country, and vice versa. Some examples of instruments used are:

- Distance: McKenzie et. al. (2006) use distance from the New Zealand consulate in Tonga as an instrument for migration when looking at impacts on the migrant in New Zealand. Distance from US border could be used in Mexican migration research, for looking at outcomes in the United States. The argument is that distance correlates with migration probability but not with "earning potential" abroad. However, since distance from the border or from the city is likely to affect outcomes in the home country, these variables would not be suitable as instruments for migration when examining the impact of migration on families in Tonga and Mexico.

- Natural shock: Munshi (2003) uses rainfall in Mexican villages as an instrument for migration, again when looking at outcomes abroad. This would not be an appropriate instrument for looking at outcomes in Mexico, since rainfall shocks could also affect health and income-earning opportunities at home.

- Cultural, historical, community and political factors. Mansuri (2006b) exploits seclusion restrictions on women in Pakistan that require the presence of at least one adult male in the household and includes household composition as a part of her instrument when measuring migration's impact on child nutrition. Hildebrandt and McKenzie (2005) use historic, 1920s, state-level migration rates in Mexico as an instrument for current migration stocks, arguing that they don't affect child health outcomes over seventy years later, apart from their influence through current migration. Mansuri (2006b,c), Acosta (2006) or Beaudouin (2005) use migration networks and history (at the village or household level) as instruments for migration (or remittances) postulating that these variables have a positive impact on the opportunity to migrate but no additional impact on income, schooling or nutrition at home. These network variables may be suitable for looking at outcomes in the home country, but can be poor instruments for looking at outcomes abroad, since, for example, a larger migrant network can help migrants abroad earn more. See McKenzie et. al. (2006) for demonstration of how poorly networks perform as an instrument when used for overseas outcomes.

- Economic shocks. Yang and Martinez (2005) and Yang (2006) exploit the "natural experiment" of the 1997 Asian financial crisis to construct an interesting instrument for remittances (not migration). Namely, different rates of depreciation of different currencies introduced an exogenous (migration-independent) variation in the peso value of remittances obtained by Philippine households with migrants in different countries. McKenzie and Rapoport (2006) uses divergence in demand for labor (proxied by 
unemployment) in the US states to instrument for migration in Mexican communities traditionally sending migrants to different US states. Such shocks are useful as instruments when looking at outcomes in sending communities, but will not be useful instruments when looking at outcomes for the migrants while abroad.

Validity of the instrument should be discussed as a matter of good practice. In the first place, one should have a compelling well-grounded story motivating the choice of instrument. Second, one should test the relevance of the instrument. Finally, one should contemplate threats to the instrument's exogeneity. For example, Mansuri (2006c) worries that migration prevalence rates in origin communities instrumenting for the opportunity to migrate can be influenced by an unobserved community characteristics such as quality of healthcare services - that also influence household health outcomes. Hildebrandt and McKenzie (2005) ponder whether the pattern and timing of the development of the railroads in 1920s Mexico (instrumenting current migration), in addition to spurring past migration, led to increased economic development and, in particular, expanded health infrastructure. McKenzie and Rapoport (2006), researching migration-inequality links and using past migration to instrument for current migration, worry that persistent inequality was a factor determining migration both historically and at present.

Estimation of instrumental variable (IV) regression is usually done through two-stages least square technique, namely: outcome $=\alpha+\beta^{*} \mathrm{M}^{\text {hat }}+\gamma^{*} \mathrm{X}+\varepsilon$ (second stage) where $M^{\text {hat }}$ is predicted from $M=\alpha_{1}+\beta_{1} *$ instrument $+\gamma_{1} * X_{1}+\varepsilon_{1}$ (first stage). When $M$ and/or outcome are binary variables (migration status or child mortality) binary choice models arise that can be (but do not necessarily have to be) estimated via probit. Some additional biases appear that are addressed by "IV-probit" procedures. However, in principle all these methods should yield similar results.

Usual caution applies when interpreting results. In the first place, results from instrumental variables apply only to a population whose behavior can be affected by the instrument. Second, magnitudes matter: so what that $10 \%$ more migration halves illiteracy, if $99.9 \%$ of population is literate? Finally, coefficients from binary choice models should be interpreted cautiously.

What if there is no good instrument? One solution is to have an idea (a prior knowledge) of which biases might be involved in a typical OLS or crosstabulation and discuss their potential implications. Alternatively, one can do a sensitivity analysis, comparing various methods and/or various instruments.

In a unique study contrasting various methods with an experimental benchmark in the context of migration, McKenzie et. al. (2006) have found that non-experimental techniques overstated gains from migration from Tonga to New Zealand, by 9 to 82 percent. A good instrumental variable (in this case a distance from the consulate) worked best ( $9 \%$ bias), while double-difference (20\% bias), single-difference ( $25 \%$ bias) and propensity-score matching (19-33\% bias, depending on whether bias-adjusted) also performed comparatively well. OLS exaggerated gains by $31 \%$, while a poor instrument 
(the size of the migrant network) exaggerated gains by $82 \%$. This was almost as large as the bias in the simple cross-country comparison of GDP per capita (100\% overstatement).

\section{FROM ANALYSIS TO POLICY RECOMMENDATIONS}

Policy conclusions do not always follow immediately from the research, and this section discusses some general issues that arise. The discussion is necessarily modest for lack of space, lack of strong evidence on policies that wok as well as the country- and contextspecific nature of migration.

Faced with growing remittances (and migration) governments feel compelled to "do something about it". However, the situation is complicated because of the private nature of these flows. Some governments have attempted to appropriate a part of the inflow, usually without spectacular successes, as such policies discourage the use of the formal financial channels. A more promising policy approach is represented by attempts to make migration and remittances "work for development". Indeed, a country can live off of remittances for a long time, but few disagree that the ultimate goal of these migration-todevelopment strategies would be to actually end the reliance on migration and remittances (Ellerman, 2003). This means, typically, creating incentives for more productive investment of remittances. However, before acting it helps to know and explain why and how to intervene.

\subsection{Rationale for intervention}

The obvious question is why to intervene at all. The ultimate objective would be to increase social welfare. However, if remittances are private money, households should know better how to spend it for their own benefit. If people prefer consumption to investment, as they usually do, this choice should be efficient and so be it. ${ }^{4}$ Moreover, some interventions could be quite inappropriate. For example, why try to convert a migrant without self-employment experience directly into a successful entrepreneur, instead of fixing the banking system so that it channels remittances to experienced profitable domestic businesses? Moreover, why fix the banking system, the investment climate and other distortions as a byproduct of migration policies, rather than as standalone reforms to benefit the domestic sector?

There are a number of answers to the question "why intervene?" and all policy advice would gain credibility from laying out and arguing grounds for policy intervention. Specifically, interventions, on efficiency grounds, are warranted when there are externalities, market failures or other distortions that drive a wedge between private and social valuation of private decisions. For example, private investment (of, say, remittances) in education and health has clear positive social externalities, and so policymakers might encourage more investment in these sectors. Also, there could be positive knowledge spillovers (returning migrants bringing know-how which benefits more people) or coordination failures. Alternatively migrant households could be myopic or financially illiterate and thus prone to making wrong decisions (from a private and/or

\footnotetext{
${ }^{4}$ Particularly if remittances are consumed by the poor who otherwise would struggle to survive.
} 
social point of view). Finally, there could be policy complementarities - for example a bad investment climate may not be a binding constraint to development while resources are lacking but will start to be one once remittances flow in.

\subsection{What policies?}

A thorough understanding of the interaction and causalities between migration and remittances on one hand and poverty and human capital on the other is a prerequisite for an effective policy. Below we organize potential policies into two groups: i) policies influencing migration and remittances directly; and ii) policies influencing channels between migration and welfare.

4.2.1. Influencing migration directly. Good research enabling determination of whether migration works to the advantage of a country in question can empower the government to act. For example, in the context of internal migration, such findings can have implications on what general development strategy to pursue, namely rural-to-urban migration or rural development. ${ }^{5}$

Policies that encourage migration can include lowering the cost and risks of migration, providing information, preparing migrants for departure, educating and taking care of them at destination, reaching out to receiving countries. ${ }^{6}$

4.2.2. Influencing the channels between migration and welfare. Good research can uncover channels through which migration operates. If a positive impact comes through remittances (independent from migration) authorities can launch policies aimed at attracting more remittances, which can include lowering transaction costs, issuing bonds to the diaspora or offering matching grants for remittances. If it is due to return migration, policies such as tax breaks, training, subsidized loans, sustaining domestic migrants' social entitlements while abroad ("portability" schemes), maintaining links and building credibility with the diaspora would be more appropriate. Furthermore, understanding why migrants' children may drop out of school can stimulate thinking on incentives for education and help design more relevant curricula or tailor more convenient schedules for migrants' children.

A relevant area of policy-oriented research is the interaction of migration with existing government programs. Certain programs may require readjustment in the light of their impact on migration, or vice versa. For example, knowledge on whether cash transfers to

\footnotetext{
${ }^{5}$ In one interesting, but perhaps extreme example Beegle, De Weerdt and Dercon (2006) find (but only after instrumenting for unobserved abilities!) that only the able move from rural-to-urban areas and gain insignificantly, so they ponder whether strategies of moving people en-masse out of poor villages to prosperous (urban) areas would actually do any good.

${ }^{6}$ Such policies are very well-developed in Philippines.
} 
the poor finance their migration or reduce incentives to migrate has important policy implications. $^{7}$

Detailed exposition of migration-related policies is beyond the scope of this note and is contained elsewhere (see e.g. Page and Plaza, 2005). However, it should be noted here that there is presently very little evidence to support the effectiveness of any of these policies, and therefore governments planning on using them should be advised to consider careful evaluation of pilot programs in order to study their impact. Underpinning this knowledge gap is a lack of good migration data - a prerequisite for sound research and policymaking.

\footnotetext{
${ }^{7}$ For example Angelucci (2005), in the context of the randomized Mexican program Progresa, finds that exogenous increase in income (such as anti-poverty transfers) cause higher international migration. At the same time conditioning grants on certain behavior (weakly) decreases migration propensity.
} 


\section{REFERENCES}

Acosta Pablo (2006), Labor Supply, School Attendance, and Remittances from International Migration: The Case of El Salvador, World Bank Policy Research Working Paper 3903

Acosta, Pablo; Calderon, Cesar; Fajnzylber, Pablo; Lopez Humberto (2006a) Remittances and Development in Latin America, The World Economy, vol. 29, Issue 7, pp. 957-987

Acosta, Pablo; Calderon, Cesar; Fajnzylber, Pablo; Lopez Humberto (2006b), What is the Impact of International Remittances on Poverty and Inequality in Latin America?, mimeo, World Bank

Angelucci, Manuela (2005), Aid programs' unintended effects: the case of Progresa and migration, University of Arizona, Tucson, mimeo

Angrist, Joshua; Krueger, Alan (2001), Instrumental Variables and the Search for Identification: From Supply and Demand to Natural Experiments, Journal of Economic Perspectives, vol. 15, no. 4, pp. 69-85

Beaudouin, Pierre (2005), Economic Impact of Migration on a Rural Area in Bangladesh, mimeo, Centre d'Economie de la Sorbonne, Universite Paris 1

Beegle, Kathleen; De Weerdt, Joachim; Dercon, Stefan (2006), Poverty and Wealth Dynamics in Tanzania: Evidence from a Tracking Survey, mimeo, Oxford University, UK

Beine, Michel; Docquier, Frédéric; Rapoport, Hillel (2006) Measuring International Skilled Migration: New Estimates Controlling for Age of Entry, World Bank Research Report, access

Docquier, Frédéric; Bhargava, Alok (2006) The Medical Brain Drain: A New Panel Data Set On Physicians' Emigration Rates (1991-2004), World Bank, access

Docquier, Frederic; Marfouk, Abdeslam (2004) Measuring the international mobility of skilled workers (1990-2000) release 1.0, World Bank Policy Research Working Papers 3381; access

Ellerman, David (2003), Policy Research on Migration and Development, World Bank Policy Research Working Paper 3117

GTAP (2005): Parsons, Christopher; Skeldon, Ronald; Walmsley, Terrie; Winters, Alan (2005) Quantifying the international bilateral movements of migrants, DRC Working Paper No WP-T13, Sussex University, UK, access

Hildebrandt, Nicole; McKenzie, David (2005), The Effects of Migration on Child Health in Mexico, World Bank Policy Research Working Paper 3573

Mansuri, Ghazala (2006a), Migration, School Attainment and Child Labor: Evidence from Rural Pakistan, World Bank Policy Research Working Paper 3945

Mansuri, Ghazala (2006b), Migration, Sex Bias, and Child Growth in Rural Pakistan, World Bank Policy Research Working Paper 3946

Mansuri, Ghazala (2006c), Temporary Migration and Rural Development, mimeo, World Bank 
McKenzie, David (2006), Socioeconomic Effects of Remittances and Migration, presented at the World Bank Migration Thematic Group workshop, September 21, 2006

McKenzie, David; Gibson John; Stillman, Steven (2006), How Important is Selection? Experimental versus Non-Experimental Measures of the Income Gains from Migration, World Bank Policy Research Working Paper 3906

McKenzie, David; Rapoport, Hillel (2006), Network effects and the dynamics of migration and inequality: theory and evidence from Mexico, mimeo, World Bank

Munshi, Kaivan (2003), Networks in the Modern Economy: Mexican Migrants in the United States Labor Market, Quarterly Journal of Economics 118 (2), pp. 549-597

OECD (2005), Database on immigrants and expatriates, OECD, Paris, access

Page, John; Plaza, Sonia (2005), Migration Remittances and Development: A Review of Global Evidence, mimeo, The World Bank

Staiger, Douglas; Stock James (1997), Instrumental variables regression with weak instruments, Econometrica 65 (3), pp. 557-86

Stecklov, Guy; Winters, Paul; Stampini, Marco; Davis, Benjamin (2003), Can Public Transfers Reduce Mexican Migration? A Study Based on Randomized Experimental Data, ESA Working Paper No. 03-16, Food and Agriculture Organization, Italy

Taylor, J. Edward; Mora, Jorge (2006) Does Migration Reshape Expenditures in Rural Households? Evidence from Mexico, World Bank Policy Research Working Paper 3842

World Bank (2006), The International Migration Agenda and the World Bank, Managing Risks Enhancing Benefits, World Bank at http://www.worldbank.org/migration

Yang, Dean (2006), International Migration, Remittances, and Household Investment: Evidence From Philippine Migrants' Exchange Rate Shocks, NBER Working Paper 12325

Yang, Dean; Martinez, Claudia (2005), Remittances and Poverty in Migrants' Home Areas: Evidence from the Philippines, background paper for World Bank's International Migration and Development Research Program, World Bank 